\section{Challenges for a New Year}

\author{
Herwig Schopper \\ EPS President
}

\begin{abstract}
Moving into a new year full of prospects and challenges stimulates a reflection of all that has been achieved in the past year and the tasks which have to be tackled in the future. The Society can be proud of the progress made in 1995, and it is tempting to describe some aspects in detail. But it seems more important to look ahead and to prepare ourselves for the new challenges that we shall have to face.
\end{abstract}

At a time when economic issues dominate the thinking of politicians it has become crucial to convince the general public that science, including physics which represents an important part, is needed more than ever before if society is to draw the greatest possible benefits from technological progress. This is, of course, not only a matter of communication with the outside, for we also have to make a considerable effort to promote physics within our community. EPS, together with its member societies, has an important role to play in both aspects.

The activities of Divisions, Interdivisional Groups, Action Committees, and other bodies are the main "tools" which are available to EPS. In order for them to be successful the Society's members must participate fully and give them their wholehearted support. The work of the Divisions and Groups is of particular importance for the development of our field. The new EPS Constitution which was formally approved in 1994 makes it possible for all members of national member societies to participate in divisional activities. I appeal to National Society Members to use this opportunity to the maximum, for the Society's effectiveness is basically the sum of the services and opportunities provided by its members.

A few specific problems which we shall have to deal with need to be mentioned. The relations between basic and applied research (and between academic and industrial activities) have to be developed, notwithstanding the fact that in many instances any differentiation is somewhat artificial and does not make much sense. Second, the examination of the best way to stimulate east-west cooperation must continue. Third, employment prospects for young physicists should become a special concern. New initiatives covering each of these themes have already been launched or are under consideration by all the Society's bodies.
The new year also sees a new era for Europhysics News. The bulletin is the most important means for communication within the Society and for strengthening the links between EPS and members of national societies. Particular effort is being made to boost its appeal. A contract was signed with Springer Verlag last year in order to put Europhysics News on a sounder technical and financial basis. As from January 1996, Springer takes care of the production and commercial aspects. Editorial responsibility, however, remains completely with EPS, as in the past. The new arrangement will hopefully make

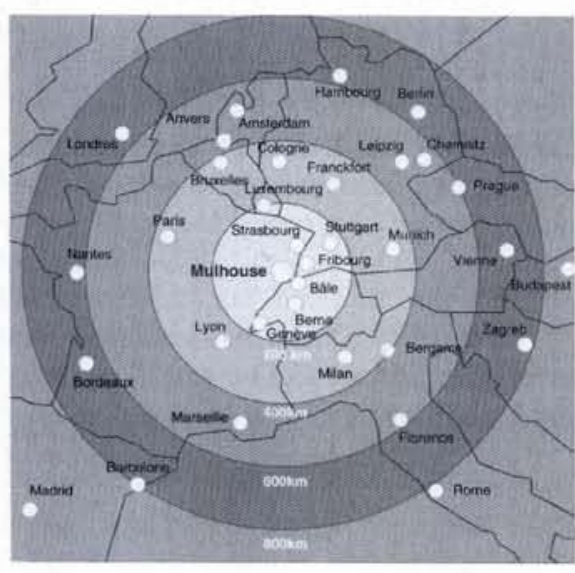

The 1996 EPS Council in March in Lisbon will vote upon an Executive Committee proposal to consolidate the EPS Secretariat in Mulhouse, France.

Europhysics News an even more attractive and lively journal. New rubrics are foreseen and the possibility to express personal opinions, thus starting a dialogue between readers, the Editor and persons holding office in EPS, will be emphasised. I encourage everybody to use the new opportunities to raise problems of topical importance, to comment on existing ones, and to express criticism.

Although the quality of EPS activities depends crucially on the personal support it receives from individuals, a sound finan- cial basis is also indispensable. I am aware that the financial contributions to EPS represent a considerable load for most National Member Societies, and a real sacrifice for a few of them. The EPS management is obliged to make the most efficient use of the contributions. To improve the situation, the Executive Committee has decided to propose to Council in March to move the EPS Secretariat from Geneva and Budapest to Mulhouse. The main reasons for this deci-sion derive from the financial aspects: cost levels in Geneva are extremely high and the Swiss franc is overvalued owing, in part, to speculation (contributions are therefore expensive, in terms of national currencies, without providing significant additional advantages).

Fortunately, we received several offers from National Member Societies to locate the Secretariat in their countries. Choosing between them has not been easy. Mulhouse, a medium-sized French town some $50 \mathrm{~km}$ north of Basle, was finally selected after a careful study of all the important factors. It was favoured mainly because the region based on Mulhouse is making a major effort to establish a European dimension. The Secretariat would be located fairly close to the Mulhouse campus of the Université de Haute-Alsace, and a generous offer of rent-free rooms for 10 years with a bilingual secretary has been made. The move should eventually result in considerable savings which I hope can be used to a large part to intensify EPS activities. An additional advantage is location in a European Union Member State, which should facilitate our relations with the European Commission in Brussels. Of course, such a move must be carefully planned and it requires sacrifices and a considerable motivation from all the staff concerned.

Coupled with the move of the Secretariat, the Executive Committee will also propose to Council to change the currency of the EPS unit fee from the Swiss franc to the ECU (and eventually to the Euro). In the future, this should relieve the financial burden on members. The ECU is averaged over several European currencies so it reflects in a more reasonable way Europe's overall economic situation.

These are only a few of the challenges which we shall have to face in 1996. I trust that all members will support the people who guide and manage our Society, especially the Executive Committee, in order to make it stronger and more efficient in every aspect, for the benefit of our science, for a better Europe and for a closer world-wide cooperation. 